lapsed on the fifth day and died. A partial autopsy showed no hemorrhage nor peritonitis.

In 8 cases I have met with stones in the common duct, in 5 stones were also found in the gall bladder. In 3 of these cases $I$ opened the gall bladder, removing the stones by a cholecystostomy and crushing stones in the common duct by fingers or padded forceps-all three recovered. In 2 cases 1 opened the common duct only; first finding from exploration through the common duct a rudimentary or contracted gall bladder and after draining the common duct with rubber drainage-both cases recovered.

In 3 cases I opened both the gall bladder and common duct to remove stones. Two died.

CASE 4.-One a woman, 49 years of age, a sufferer for nine years, and intensely jaundiced for nine months before operation. Two stones were removed, one a centimeter in diameter, from the gall bladder, and one slightly larger from the common duct. The common duct was drained, but the patient died from cholemic hemorrhage the second day.

CASE 5.-The second death was in a feeble Armenian, 39 years of agre, who had suffered fifteen years and had been deep bronze color for months. I removed from him also one stone from the gall bladder and one from the retroduodenal portion of the conmon duct. During the month he lived after operation his temperature remained normal or slightly below, and on the thirtieth day he suddenly died from heart collapse, due as much to innutrition as anything. The autopsy showed no peritonitis nor hemorrhage, but great wasting of all tissues.

Of 2 cholecystectomies which $I$ have done on patients who had suffered from gallstones one died.

CASE 6.-The patient was a man 55 years of age, whom I saw in consultation eight years ago, at which time $I$ urged him to have an operation. At that time the attacks of pain were of great severity and recurred very frequently, but he would not entertain the thought of operation. During the eight years which elapsed he was frequently incapacitated by pain and jaundice from labor, and increasing doses of morphin became necessary to give him any comfort. Just before operation he had required one-half grain doses of morphin every three or four hours. I urged operation, and removed a gall bladder, pear-sllaped, and about six inches long. The gall bladder contained no stones, but its walls were very much thickened and the mucous membrane very much thickened, infiamed and in some places necrotic. No stone could be detected in the common duct. The cystic duct was ligatured and overeast and the abdomen tamponed. His vessels were selerosed. During the ten days he lived he had, with increasing frequency, attacks of lividity, of hands and weak pulse, but practically a normal or slightly subnormal temperature. The stools, previously white, became normal after operation and he had absolutely no pain. His appetite was fickle and death came with a collapse. No autopsy was allowed.

\section{BROMID OF ETHYL IN ADENOTOMY AND TONSILLOTOMY.*}

\section{A. R. SOLENBERGER, M.D.}

COLOKADO SPRINGS, COLO.

GENERAL STATEMENTS.

I wish to preface this study on bromid of ethyl with a few statements, which, though they apply to the use of any one of the general anesthetics in adenotomy and tonsillotomy, yet they more naturally formulate and have particular application in the use of bromid of ethyl in the operations we wish to consider. They will not only serve the operator as guiding principles, but will foreshadow the general limitations of ethyl bromid in operations on adenoids and diseased tonsils.

* Read before the El Paso County Medical Soclety, Colorado Springs.
1. If an indication is found for the removal of tonsillar or adenoid tissue, a minute differential diagnosis of the pathologic condition is absolutely imperative. Otherwise there can be no scientific remedial disposal made of it. There will be selected an improper method of operation, either in the choice of the most suitable anesthetic or of the instruments best adapted. Not only must the eye make an exact measurement of the diameters of the tonsil in its largest dimensions, but it must determine the degree in which the tonsil is sessile or pedunculated, adherent to or free from the faucial pillars, soft, with a tough fibroid frame work or hard fibroid throughout, and whether the peritonsillar areas, including the accessory glands, contain any products of old inflammations.

Of the products of the pharyngeal vault, the mind must not only be ready for an impression of a possible enlarged third tonsil, but for the probability of scattered adenoid crypts, extending around and into the eustachian orifices and down the posterior pharyngeal wall, and even into the posterior nares. Then, and only then, can the operator select the proper anesthetic and the proper instruments.

2. When the indication for operation has been found, the operation should meet completely the indication, that is, it should be done thoronghly.

3. The pain, excitement and shock incident to tonsillotomy and adenotomy make general ancsthesia necessary in the large majority of children, and very desirable in all.

4. Even in the former class, that is, in phlegmatic or robust children, local anesthesia does not entirely relieve pain nor insure against undue shock and subsequent prostration.

5. I wish this present study to apply to children only between the ages of 1 and 12 ; since before the age of one and after the twelfth year, local anesthesia usually suffices.

\section{AN IDEAL ANESTHETIC DEFINED.}

From these prefatory statements, I think it will naturally follow that the thoroughly scientific operator will choose between one of the several anesthetics, just as he will select from the many kinds of instruments those which are most suitable to the particular kinds of pathologic tonsillar or adenoid conditions in hand, as well as to adapt the anesthesia and instruments to the age and temperament of the patient.

The properties of an ideal anesthetic should possess:

1. The element of perfect safety.

2. The element of endurance; should benumb long enough to admit of a thorough operation.

3. The element of rapidity of action.

4. Should be pleasurable, non-excitant, a muscular relaxant and respiratory sedative. The latter element should not be so complete as to abolish entirely the respiratory reflexes.

5. Should allow the patient to be placed in the sitting position.

BROMID OF ETYYL IN TJEE LITERATURE.

Such an ideal ancsthetic has not yet been found, but in bromid of ethył we have, perhaps, one that satisfies these demands more nearly than any other in operations on a certain class of cases of adenoids and diseased tonsils of children.

The use of bromid of ethyl, while it meets these demands perfectly only in properly selected cases, must therefore have definite limitations.

It will be the object of this paper to point out these 
limitations and endeavor to establish its legitimate place among the general anesthetics.

The safety of an anesthetic is no doubt always of the first importance. Everything else should be sacrificed for this. Ether is, of course, generally understood to have the best statistic record for safety. Yet mortality reports for bromid of ethyl seem to have in recent years been as favorable as for ether.

Gurlt $^{1}$ (1892) finds one death in 4,550 cases against one death for A.C.E. in 4,118 cases. Later (1894) the same author reports one death in 3,662 cases. Chisholm ${ }^{2}$ (1895) used it in 3,000 cases without a death. Gilles ${ }^{3}$ (1896) collected 20,000 cases of its administration without a fatality. Hoddes ${ }^{4}$ (1899) reports 40,000 cases, in most of which there was no previous examination of the patjent and in some enormous doses were given, yet not a single death occurred. Reich ${ }^{5}(1900)$ in a most comprehensive survey of the literature found 16 deaths in 60,000 cases. In some of these he found the deaths were due to some of the mistakes of administration, which will be referred to later in this paper.

Theime; and Hoffmann ${ }^{7}$ each reports cases of death in which toxic symptoms began 24 hours after administration when the autopsy showed parenchymatous degeneration of the heart.

However, in nearly all of the fatal cases from the full record it will be seen that the autopsy revealed pathologic conditions which were present before the anesthetic was administered, either in heart, kidneys or liver. Again, all of these fatal cases were above the age of 20 years.

In all the literature at my command I have not been able to find a death in a child. My own experience with its use covers a period of five years, having administered it in 50 cases in the clinics of the laryngologic department of the Northwestern University, and in about the same number of cases in private practice. I have seen only two cases in which the symptoms were at all alarming, and in one of these I could attribute them to faulty administration and the other to the impurity of the drug.

On surveying the earlier literature it will be found that some fatalities are recorded, but that the number decreases as the proper methods of its administration were learned and proper limitations to its use were made, until in recent years there seem to have been a few deaths as there also have been with ether and chloroform.

\section{PRECAUTIONS TO BE OBSERVED.}

I have thus come to believe that bromid of ethyl is a perfectly safe anesthetic when given to a healthy child and under certain precautions. To insure the maximum of safety:

1. There should be a reasonable certainty of the healthiness of the lungs, liver and kidneys. The fact that the child is delicate does not contraindicate its use. Such a child needs simply a smaller dose and will come under anesthesia quicker. The stomach must be empty and the chest unrestricted by the clothing or the arm of the assistant. The precautions necessary to eliminate all danger are based on the known characteristics and physiologic action of the drug; therefore,

2. The drug should be pure. The mistake of using bromid of ethylene should be avoided. This mistake has unfortunately been made. The free bromin which the ethylene specimen contains was responsible for the death of Labardio's ${ }^{9}$ case, in which death was due to syncope occasioned from reflex nasal and bronchial irritation of the bromin. The pure specimen is only to be found in scal-brown glass tubes, which were sealed instantly, perfectly volatile, sweet (not garlicky), colorless and non-residuous. I always make it a practice to test the specimen even from these tubes by pouring the proper quantity in a graduate and a little of it on the hand before its administration.

3. It should be given en masse. This is imperative, as will be seen from a study of its physiologic action, for it acts directly on the nerve centers, not as an irritant like chloroform, but paralyzes these centers almost immediately. Hence there is no stage of excitement and no initial laryngeal reflex, and little or no muscular rigidity. The brain paralysis is at once followed by dilatation of the cerebral vessels, producing congestion of the brain for a certain period before the heart can be affected. This explains why the sitting posture, so frequently desirable in these operations, is not only perfectly admissible, but an element of safety.

But if now the anesthesia is pushed beyond this brain congestion limit or the brain condition in which the sensitive reflexes are abolished, quite another state is induced which becomes dangerous. This more prolonged cerebral paralysis favors the formation of chemical toxic compounds with the protoplasm of the cortex and other centers, which may prove rapidly fatal, especially when there is organic disease present. ${ }^{\circ}$

Then, as its safety and success depends on the power of the anesthetic to produce prompt and uninterrupted but limited paralysis, the cone containing the drug should exclude all air and be kept in position till cerebral paralysis and relaxation is complete, and under no circumstances should the cone be reapplied. If air is at all admitted, excitement and rigor result, and if reapplied it is apt to act as an irritant to the brain instead of a sedative, and finally result in dangerous paralysis of the respiratory centers.

4. Time required for anesthesia: No hard and fast rules can be given as to the length of time the cone should be held in place. nor the exact quantity poured into the cone. Both will depend on the temperament of the patient or nerve tone. I have found $5 \mathrm{gm}$. sufficient for children under 5 years, and $10 \mathrm{gm}$. the maximum dose up to the age of 12 years, and the time of administration from 20 seconds to 40 seconds. At least operations can always begin one minute after the beginning of administration.

I prefer to give it myself, keeping hold of the disengaged arm with finger on pulse, watching respiration and tone of the arm and neck muscles, but more especially of the eyes, which remain open, for dilitation of the pupils and suffusion of the conjunctivæ. If then the proper moment is chosen for commencement of operation the operator can count on about two minutes for work, after which the patient becomes almost immediately conscious and is able to walk and has no uncomfortable sensations.

\section{RULES FOR USE.}

In tracing the causes of the fatal cases recorded, we then have formulated in a negative way the rules for its administration:

1. Do not use bromid of ethylene.

2. Do not use an old or impure solution.

3. Do not administer it in repeated and small quantities. Give en masse, admit no air.

4. Do not continue its administration longer than one minute.

The utility of such an ephemeral anesthetic; aside 
from its safety, will depend largely on three other conditions:

1. On the dexterity of the operator.

2 . On the nature of the pathologic structures.

3. On the possibility of constructing instruments to thoroughly remove the diseased tissues in the given time with the least number of assistants.

The dexterity necessary is perhaps greater than the ordinary operator possesses or one who is not accustomed to cavity operations, but some possess this dexterity by nature, and all those who work in cavities can acquire it.

As to the diseased structures of the tonsils and pharyngeal vault, if both operations are in question and are to be thoroughly done with this anesthetic, the tonsils must be pedunculated, or at least not adherent to the pillars of the fauces, nor must they be entirely submerged under thickened columnar folds. The adenoids must be located in the vault centrally or en masse. If the tonsils are sessile or very soft and their frame work toughly fibroid, and the adenoids projecting into the posterior nares, the crypts scattered or actually growing around the eustachian orifices and extending down the posterior wall of the pharynx, as is not infrequently the case, then a thorough removal is not possible with the two-minute anesthesia of bromid of ethyl.

Here, then, comes the limitation of its use, even when the single operation is desired, viz., in the case of the tonsils when they are small sessile, adherent or submerged, and in the case of the adenoids when they are growing from many points and are of such consistency as makes it impossible to remove them with three or four sweeps of the curette.

Yet the somewhat large opportunity I have had for the study of these pathologic adenoid tissues has convinced me that the number of cases suitable for this rapid operation are quite large enough to stimulate careful differential diagnosis, and to justify the construction of instruments, especially adapted for the use of this simple and brief anesthetic. Our endeavors to thus enlarge the use of this anesthetic should be further stimulated by the assurance that many more children who are now suffering from the numerous pernicious deformities occasioned from mouth breathing could be made to submit to this comparatively inexpensive and simple operation, while they now too often are allowed to shrink from the more formidable one of a prolonged anesthetic.

\section{THE INSTRUMENTS NEEDED.}

For the removal of the tonsils with bromid of ethyl I have not found an instrument (admirable as some are under other forms of anesthesia) which I could work rapidly enough, especially when the double operations of adenoids and tonsils are to be done. There is not time to empty the forked instruments of the cut-off tonsils. If these were used two of the same size would be required, and all other forms of guillotines would require a third assistant to depress the tongue.

To make bromid of ethyl practical and simplify the whole operation, an instrument is needed that can not only be worked rapidly, but worked with one hand, leaving the other free to depress the tongue, thus dispensing with a third assistant and one which could be directly transferred to the opposite tonsil, completing the excursion of the tonsils in 45 seconds.

I think I have succeeded in modifying the McKenzie guillotine so as to practically fulfill these conditions. I have placed a thumb ring on the heel of the blade and a counter support ring beneath the frame for the index finger to enable the operator to open the fenestrum with one hand. I have also reduced the thickness of the blade and the thickness of the fenestrum ring, thus allowing the ring to burrow more deeply and to more completely surround the tonsil and securing a much closer shave. Then, besides the advantage of rapidity of execution, the pressure one can exert in getting around even a partially submerged tonsil and forcing them into this thin fenestrum ring is much greater and more accurate than is possible with any self-acting forked guillotine.

There are other features of the instrument which have a wider application than its use with bromid of ethyl, features which apply to construction of tonsillotomes in general. The father of English laryngology conceived the true mechanical principles of tonsillotome construction for all time, viz.:

1. That in all cavity work the hand power should be applied at a point parallel to but out of the way of the visual line and the axial line which carries the exerted force.

2. Simplicity of construction, necessary to instrumental asepsis.

While it is true that successful cavity work depends much on the man behind the instrument, yet the instru-

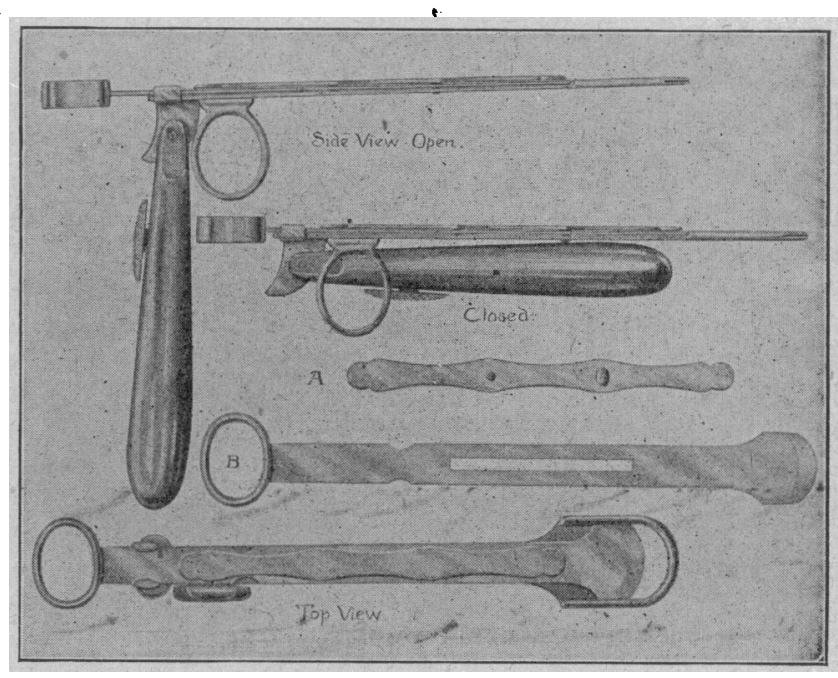

ment which is constructed in accordance with true scientific principles is the best, alike for the hand of the beginner and the experienced operator, and while this guillotine is presented on the merits of special adaptation, it has also the utility of a very broad application.

Not many years ago one heard frequent discussions as to how much of the tonsillar stumps ought to be left. Now the pathologist says, "Leave no stump," "enucleate the tonsil." Surely in all cases all the diseased tissue should be removed, and that means all the enlarged adenoid tissue, and that means all the tissue which by reason of its being diseased more easily absorbs microorganisms and all tissues which interfere with normal nasal respiration. It is not good science to leave any of this behind in the hope that if a part is removed the remnant will "shrink up." This applies both to the lean, nervous, poorly nourished, as well as to the lymphatic or phlegmatic child. The adenoid base should in most cases be removed. This is what is meant by the "operation completely meeting the indication." This is what is meant by thorough work. This can be done with this guillotine under bromid of ethyl, if we limit 
its use to the fairly free pedunculated cases; in these one can shave through the pedicle beyond the crypts.

\section{. SUMMARY.}

To epitomize: For the brief anesthesia of bromid of ethyl all of the forked guillotines and the old patterns of McKenzie are too slow and too clumsy, and those which are intended for the associate use of the vulsellum and the cold snare, while they are the most scientific under chloroform or ether, are not practical under bromid of ethyl.

To make bromid of ethyl thoroughly effective it must be limited to certain carefully selected cases and the use of a guillotine whose fenestrum can be opened with one hand, and the blade and fenestrum ring as thin as adequate strength will permit, and to allow of a hand grasp at once comfortable and so firm that the tonsil can be crowded into the fenestrum to its fullost extent with a precision and quickness commensurate with the ephemeral nature of the anesthetic. To insure this thorough work it will be readily seen that the fenestrum ring must exactly fit the tonsil; hence at least three children's sizes of this tonsillotome are necessary.

The child is wrapped in a stout sheet, firmly pinned, with one arm free and held by the assistant in the intubation position, the gag is then placed and the cone immediately applied. When the anesthesia is complete, as indicated by the above-mentioned signs, and the first 45 seconds have been consumed in excising the tonsils, at least one minute of unconsciousness is left to clear the vault.

For the removal of the adenoids I have found Dr. Casselberry's guillotine as modified by Dr. Gradle quite satisfactory when the growth is simply the enlarged third tonsil centrally located in the vault. When, however, the adenoids extend slightly beyond this area I use the Delstaunch modification of the Gottstein curette, making a central sweep, securing the greater part of the mass in its teeth, then follow with the Kirstein curette. With the latter one can lift up the soft palate to secure a large view of the vault and shave more safely and close to the eustachian orifices. The head of the patient is then quickly brought forward while there is usually still time to enter the vault with the finger to remove any possible remnants.

Finally, as to the technic this method demands: While it is true that it requires great dexterity and accuracy, yet if this is once acquired it seems to me it is more simple than any other method.

Certainly the operator who can do well this double operation with bromid of ethyl would extend the beneficence of these operations to a much greater number of sufferers, for many of the profession and laity who know the baneful consequences of mouth breathing shrink from the remedy, because of the formidableness and great expense of other methods.

But suppose the operator has not this dexterity or the pathologic structures are not suited to the use of ethyl bromid, or this particular structure of instrument is not at hand, then either the tonsillotomy and adenotomy may still be done at two different sittings with bromid of ethyl, since this anesthetic causes so little inconvenience; so I would still speak for bromid of ethyl, but not necessarily for this particular instrument. On the other hand, if the tonsils are sessile or submerged, and require drawing out with the vulsellum, and therefore another anesthetic which will insure longer time, this instrument will still prove more accurate than any with a self-acting fork like the Mathieu's, for the operator can perfectly control and measure with the vulsellum, in the presence of the firm and steady grasp which this instrument gives to the operator, the exact quantity of tonsillar tissue to be removed.

\section{LITERATURE.}

1. Gurlt, T.: Arch. of Clin. Chir., 1892, vol. xIv, pp. 55-113.

2. Chisholm : Med. Standard, October, 1900

3. Gilles: Turnbull's Artificial Anesthesia.

4. Hoddes: Deutsche Monatsschrift für Zahnheilkunde, 1892 vol. $x$, October, 1892 , pp. 411 to 435

5. Reich: Wiener Med. Woch., 1893 , vol xliii, p. 1090 etc. : Dr. Emst Hankel's Handbook Artificial Anesthesia. Leipzig, 1898

6. Theime: Deutsche Med. Ztg., 1800. No.5\%

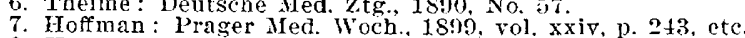

9. Hacmes: or Vose Helikf, No. 2, 1890 . (b) Thornton Meixell : The College and Clinical Record. Phila., 1892 . vol. xiji. p. 245 , etc. $(c)$ Hoddes: Same as above. (d) Marvel: American Med icine, 1901. vol, ii, p. 657. (e) Golden: N. Y. Med. Journal, 1901 Dec. 14

\section{RUPTURE OF GALL BLADDER OR DUCT FROM VOMITING.}

WITH RUPTURE OF APPENDIX IN SAME PATIENT; TWO CASES OE APPENDICTTIS; ACUTE YELLOW ATROPIIY OF TIIE LIVER.*

W. W. GRANT, M.D.

DENVER.

RUPTURE ŌF GALL BLADDER OR DUCT.

CASE 1.-A. C. D., aged 53. Four years ago, I am informed, he had two attacks of colic. Aug. 1, 1902, had an attack that resembled biliary colic. In each instance recovered promptly, with no evidence of gallstone in the intervals.

On September 1 last I was called at 2 a. m. to see this patient, who was suffering severely from colic, with greatest pain over gall bladder. He was given a hypodermic of morphia and atropia, hot applications to abdomen. He became easier and 1 returned home. Two hours later I was again called. He had been vomiting and his pain was now excruciating, and there was marked rigidity of abdominal muscles, with decided localization of pain under the right costal arch. I believed perforation of gall bladder or duct was imminent or had occurred. I returned at 8 o'clock, when his temperature was $102 \frac{1}{2}$; rigidity of muscles increased, with increasing tenderness over right epigastrium to vicinity of appendix. I advised immediate operation, but called Dr. Leonard Freeman in consultation. He thought there was evidence of gall bladder disease, but that the appendix was the main source of trouble, and also urged immediate operation, but I could not get the patient on the operating table before $3 \mathrm{p} . \mathrm{m}$., when patient's temperature was $103 \frac{1}{2}$. Appendix was first removed. It contained no pus, but was cystic and ruptured at apex. Bile flowed freely from this wound as soon as peritoneum was opened, which demonstrated what $\mathbf{I}$ suspected. An incision was made immediately over gall bladder and bile escaped freely in larger quantity, with some thick grumous bile-stained material. Several gallons of warm salt solution were used in the abdomen through both wounds before the water escaped free from bile. The abdominal wall was fat and very thick. The gall bladder was collapsed completely and could not be brought into the wound nor into good view. No stone could be felt in the ducts. The patient had a weak (probably fatty) heart, and his condition was so bad under anesthesia that death seemed imminent; so the operation could not be prolonged, though he was on the table little less than an hour. The exact location of the rupture was, therefore, not determined. Dr. Freeman held the fundus of the bladder with forceps while I packed gauze well around it. His extreme condition necessitated great haste and an unsatisfactory conclusion of the operation. In fact, we were greatly relieved that he did not die on the table. He reacted fairly well. His temperature deelined to 99 for two days and then fluctuated between $991 / \mathrm{z}$ and $101 \frac{1}{2}$ for two days more, when he died from septic peritonitis. His heart remained weak, and nausea vomiting prevented any nourishment by stomach. I regret very much that

* Read at the twelfth annual meeting of the Western Surgical and Gynecological Association, held at St. Joseph, Mo., December
29 and 30,1902 . 